EXTENDED REPORT

\title{
El48Q is a disease-causing MEFV mutation: a phenotypic evaluation in patients with familial Mediterranean fever
}

\author{
R Topaloglu, F Ozaltin, E Yilmaz, S Ozen, B Balci, N Besbas, A Bakkaloglu
}

See end of article for authors' affiliations

Correspondence to: Professor Rezan Topaloglu, Hacettepe University Faculty of Medicine Department of Paediatric Nephrology and Rheumatology, 06100 Ankara, Turkey; rtopalog@.hacettepe. edu.tr

Accepted

18 September 2004

Published Online First 30 September 2004
Background: Familial Mediterranean fever (FMF) is one of the periodic fever syndromes. It is common among Turks, Jews, Arabs, and Armenians. Several mutations in the MEFV gene, including E148Q, have been identified as causing this disease. It has been suggested that the E148Q mutation is the mildest mutation and some reports have questioned its disease association.

Objective: To evaluate the phenotypic features of the patients with $E 148 \mathrm{Q}$ mutation.

Subjects: 26 patients homozygous for $E 148 Q, 10$ compound heterozygous for $E 148 Q$, and eight complex cases were assessed.

Results: Although four of the 26 patients with $\mathrm{E} 148 \mathrm{~A} / \mathrm{E} 148 \mathrm{Q}$ were asymptomatic at the time of evaluation, abdominal pain was seen in $77 \%$ of the patients, fever in $66 \%$, arthralgia in $50 \%$, arthritis in $15.4 \%$, and vomiting in $23.8 \%$. Compound heterozygotes and complex cases had a higher frequency of abdominal pain, fever, arthralgia, arthritis, myalgia, and chest pain than subjects who were homozygous for E148Q, but none of these symptoms reached statistical significance. None of our patients had amyloidosis but two with E148Q/E $48 \mathrm{Q}$ had a family history of amyloidosis and one had rapidly progressive glomerulonephritis secondary to vasculitis, which progressed to chronic renal failure.

Conclusions: Patients homozygous for E148Q have a heterogeneous clinical presentation. Most are symptomatic and colchicine treatment is required in these patients.
$\mathrm{F}$ milial Mediterranean fever (FMF) is an autosoma recessive disease affecting mainly Turks, Jews, Armenians, and Arabs. It is characterised by recurrent short episodes of fever, sterile peritonitis, arthritis, and pleurisy. Attacks are accompanied by a strong acute phase response and the most severe complication is the development of renal amyloidosis. ${ }^{1}$ The gene responsible for FMF, MEFV, was identified by positional cloning in $1997 .{ }^{23}$ It is located on chromosome 16p13.3 and compriseslo exons and 781 codons. The product of the MEFV gene, named pyrin/Marenostrin, is expressed in polymorphonuclear cells and monocytes and it is proposed that it regulates inflammatory responses at the level of leucocyte cytoskeletal organisation. ${ }^{4}$ Thirty six mutations located in the MEFV gene have been identified so far, mostly in exon 10, followed by exons 2, 3, 5, 1, and 9. Four of five founder mutations-M694V, V726A, M680I, and M694I-are located in exon 10 and E148Q in exon 2. ${ }^{5}$ These founder mutations account for $74 \%$ of FMF chromosomes in typical patients from the Mediterranean basin. ${ }^{5} \mathrm{M} 694 \mathrm{~V}$ is found to be the most common mutation in North African Jews, with more than $70 \%$ allele frequency; $\mathrm{V} 726 \mathrm{~A}$ is predominant in Ashkenazi and Iraqi Jews, Armenians, and Arabs. ${ }^{6}$ Allele frequencies in Turkey have been published from two independent centres. ${ }^{78}$ Yalcinkaya et $a l^{7}$ reported the allele frequencies in patients as follows: M694V 43.5\%, M680I $13.0 \%$, V726A $11.1 \%$, and M694I 2.8\% for the four founder mutations, and most recently our group reported the five most common founder mutation frequencies as follows: M694V 51.5\%, M680I 9.2\%, E148Q 3.6\%, V726A 2.9\%, and M694I $0.4 \%{ }^{8}$

The carrier frequency of the E148Q mutation has been reported to be $12 \%$ in Turks, $10 \%$ in Ashkenazi Jews, $6.4 \%$ in Jews of Moroccan origin, and as high as 53\% in Jews from the various ethnic groups..$^{8-10}$ Because carrier frequencies were far higher among healthy carriers than among patients with FMF, it has been proposed that E148Q is a polymorphism, not a disease causing mutation, and has a low penetrance..$^{9-12}$

As El48Q is one of the common mutations in Turkish patients with FMF, our aim in this study was to evaluate the phenotypic features of Turkish FMF patients with the E148Q mutation in homozygous, heterozygous, and complex states in order to shed light on the clinical presentation of this mutation.

\section{METHODS}

Molecular diagnosis of FMF at our institution began in 1999 by screening the four most common MEFV mutations, followed by screening 14 MEFV mutations in exon 10 along with E148Q in exon 2 in 2000. The patients with FMF diagnosed at our department, and in whom MEFV mutation analysis was available between the years 2000 and 2003, were screened retrospectively. Forty four of 2723 patients were either homozygous or heterozygous for the E148Q mutation and these were enrolled in the current evaluation. Twenty six patients were homozygous for E148Q, 10 were compound heterozygotes, and eight had complex mutations. Only four of 26 patients who were homozygous for E148Q-detected through family studies-were asymptomatic at the time of evaluation and remained asymptomatic during the follow up for two to four years. None of these had received colchicine before testing.

The diagnosis of FMF was established according to previously described criteria. ${ }^{1}$ These patients were seen again and the patient file was reviewed and updated by the same physician. Clinical information included age of onset,

Abbreviations: FMF, familial Mediterranean fever 


\begin{tabular}{|c|c|c|}
\hline Variable & $\begin{array}{l}E 148 Q / E 148 Q \\
(n=26)\end{array}$ & $\begin{array}{l}\text { E148Q compound and } \\
\text { complex }(n=18)\end{array}$ \\
\hline $\begin{array}{l}\text { Age at onset (years) } \\
\text { Age at diagnosis (years) } \\
\text { Male:female }\end{array}$ & $\begin{array}{l}6(3 \text { to } 15) \\
8.5(3.5 \text { to } 16) \\
16: 10\end{array}$ & $\begin{array}{l}6.5(2 \text { to } 16) \\
8.5(3.5 \text { to } 19) \\
6: 12\end{array}$ \\
\hline \multicolumn{3}{|c|}{$\begin{array}{l}\text { Values are median (range) or } n \text {. } \\
p>0.05 \text { between the groups. }\end{array}$} \\
\hline
\end{tabular}

frequency of attacks before colchicine treatment, the presence of fever, abdominal pain, pleurisy, arthralgia, and arthritis, response to colchicine, family history of amyloidosis, and the development of amyloidosis.

\section{Mutational analysis}

Molecular diagnosis of FMF was carried out in our medical biology department. The strategy for mutation analysis involves two steps: exon 10 is first analysed by denaturing gradient gel electrophoresis; according to the band pattern, subsequent analysis is done either by restriction endonuclease enzyme digestion or by genomic sequencing. E148Q in exon 2 is analysed by restriction endonuclease enzyme digestion of polymerase chain reaction products from genomic DNA. The region harbouring the mutation was amplified and the amplified products were digested with the enzyme BstNl.

\section{Statistical analysis}

Results are given as median (range) for age and as percentages for the phenotypic features. Comparisons between groups were carried out by using Mann-Whitney $\mathrm{U}$ test and the $\chi^{2}$ test. A probability $(\mathrm{p})$ value of $<0.05$ was considered significant.

\section{RESULTS}

In the patients homozygous for E148Q the median age of onset was 6 years and the male to female ratio was 1.6 (table 1). Fever was seen in $64 \%$, abdominal pain in $76.9 \%$, arthralgia in $50 \%$, and arthritis in $15.4 \%$. None of these patient had erysipelas-like lesions or scrotal pain, but $23.8 \%$ had severe vomiting and $12.5 \%$ had diarrhoea during the attack. None had amyloidosis but three had a family history of amyloidosis. One had rapidly progressive glomerulonephritis secondary to vasculitis and progressed to chronic renal failure. Currently she is on a chronic haemodialysis programme.

Of 10 compound heterozygotes, six were carrying E148Q/ M694V, three were carrying E148Q /V726A, and one was carrying E148Q /M680I. Of eight complex cases, seven were carrying E148Q/E148Q/M694V and one was carrying E148Q/ E148Q/M694I. The age of onset and the male to female ratio were similar in the homozygous and compound/complex cases (tablel).

Although the frequencies of fever, abdominal pain, chest pain, arthralgia, arthritis, and myalgia were greater in compound heterozygous and complex cases, none of the symptoms attained statistical significance compared with patients who were homozygous for EI48Q (table 2). One of the complex cases had a history of acute rheumatic fever. It was striking that severe vomiting was observed in around $25 \%$ of the patients in both homozygous and compound/ complex cases.

\section{DISCUSSION}

Since the gene causing FMF (MEFV) was cloned and four missense mutations were identified in exon 10, several other
Table 2 Phenotypic features of the patients*

\begin{tabular}{|c|c|c|}
\hline Phenotypic feature & $\begin{array}{l}E 148 Q / E 148 Q \\
(n=26)\end{array}$ & $\begin{array}{l}\text { E148Q/others } \\
\text { E148Q/E148Q- } \\
\text { others ( } n=18)\end{array}$ \\
\hline Fever & $16(64)$ & $15(83.3)$ \\
\hline Abdominal pain & $20(80)$ & $18(100)$ \\
\hline Arthralgia & $13(50)$ & $7(38.9)$ \\
\hline Arthritis & $4(15.4)$ & $6(33.3)$ \\
\hline Chest pain & $6(23.1)$ & $8(44.4)$ \\
\hline Myalgia & $3(11.5)$ & $4(22.2)$ \\
\hline Vomiting & $5(23.8)$ & $4(22.2)$ \\
\hline Diarrhoea & $3(12.5)$ & $2(11.1)$ \\
\hline Family history of FMF & $8(36.4)$ & $7(38.9)$ \\
\hline Family history of amyloidosis & $3(11.5)$ & $3(16.6)$ \\
\hline Appendectomy & $3(11.5)$ & $4(22.2)$ \\
\hline \multicolumn{3}{|l|}{ Frequency of attacks ${ }^{*}$} \\
\hline None & $4(15.4)$ & - \\
\hline $1-10 /$ year & $16(61.5)$ & $9(52.9)$ \\
\hline $11-20$ /year & $3(11.5)$ & $3(17.6)$ \\
\hline$>20 /$ year & $3(11.5)$ & $5(29.4)$ \\
\hline \multicolumn{3}{|l|}{ Duration of attacks } \\
\hline None & $4(15.4)$ & - \\
\hline$<1$ day & $9(34.6)$ & $3(17.6)$ \\
\hline $1-2$ days & $9(34.6)$ & $10(58.8)$ \\
\hline $3-5$ days & $3(11.5)$ & $3(17.6)$ \\
\hline$>5$ days & $1(3.9)$ & $1(5.9)$ \\
\hline \multicolumn{3}{|l|}{ Response to colchicine } \\
\hline Complete & $16(72.8)$ & $12(67)$ \\
\hline Partial & $3(13.6)$ & $2(11)$ \\
\hline No response & - & $2(11)$ \\
\hline Unknown & $3(13.6)$ & $2(11)$ \\
\hline
\end{tabular}

mutations have been identified in exons 1, 2, 3, 5, 9, and 10 of the gene. ${ }^{235}$ One of these is the E148Q mutation, which results in the substitution of glutamine for glutamic acid at codon 148 in exon $2 .{ }^{11}$ It is one of the most common mutations in patients with FMF. It is more frequent in the general population than in FMF patients in the regions where FMF is prevalent, and it also occurs in geographically and ethnically diverse populations. ${ }^{5}$ As a result of the discrepancy between the prevalence of this mutation in FMF patients and in the healthy population it is thought to be a polymorphism rather than a disease causing mutation and it is claimed that homozygosity for E148Q is not sufficient for developing clinical disease. ${ }^{910} 121415$ Further, it is reported that homozygosity for E $148 \mathrm{Q}$ may influence susceptibility to polygenic conditions such as Behçet's disease and AA amyloidosis among patients with non-FMF periodic fever. ${ }^{16} 17$

In our series from Turkey, the E148Q mutation is one of the common mutations among patients with FMF, with 3.5\% allele frequency and a carrier frequency of $12 \%$ in the healthy Turkish population. While this may suggest a low penetrance of the mutation, we observed symptomatic patients not only among those compound heterozygotes and complex cases but also in cases homozygous for E148Q.

We had 26 patients who were homozygous for E148Q. While four of these (15\%) were as yet asymptomatic and were detected through family studies, the remaining patients had typical FMF attacks. During the acute attacks their acute phase reactants were raised and after an attack they returned to normal. They all had a good response to colchicine. Clinical heterogeneity is observed in patients who are homozygous for $\mathrm{E} 148 \mathrm{Q}$, ranging from absence of symptoms to severe symptoms. ${ }^{18}$ It could be suggested that we saw only patients with symptoms and that a large portion of the asymptomatic homozygotes do not present to a medical centre. On the other hand, other genetic modifiers that may link to E148Q and which are as yet unknown may play a role in enhancing the 
expression of the disease in the symptomatic homozygotes The heterogeneity of the clinical picture is not limited to the E148Q mutation; it may be seen in homozygotes for other mutations, including M694V. ${ }^{19}$ Furthermore, individuals with two MEFV mutations may present with three different clinical pictures ${ }^{6}$ :

- Phenotype I: overt FMF, which includes patients with a wide range of manifestations and mutations;

- Phenotype II: isolated amyloidosis which includes patients with this as the sole or first manifestation of the disease;

- Phenotype III: subclinical or preclinical FMF which includes all patients clinically unaffected with two MEFV mutations.

Our four patients with no symptoms at the time of evaluation may be considered as phenotype III. In terms of phenotypic features there were no differences between the homozygous and the compound heterozygous/complex cases.

None of our 44 patients had amyloidosis at the time of evaluation, but FMF associated amyloidosis in patients who are heterozygous for E148Q and in a patient homozygous for both E148Q and V726A (E148Q V726A/E148Q V726A) has been reported. ${ }^{2021}$ Although most of the previous studies showed that M694V was the leading mutation for risk of developing amyloidosis, the patients with mutations other than M694V are also prone to this complication, and some other determinants such as environmental factors and modifier genes may have additional effects. ${ }^{72}$ Furthermore, the severity of the disease course does not consistently parallel the development of amyloidosis. On the basis of this information, one cannot exclude the possibility that patients with E148Q may be at risk of developing FMF related amyloidosis.

Thus our results do not completely rule out the possibility that the E148Q mutation has an upregulating effect on inflammation in both FMF and other chronic inflammatory processes. We believe that symptomatic individuals who are homozygous for E148Q should not be ignored.

As we observed clinical heterogeneity and a high frequency of symptoms, our view is that symptomatic patients require colchicine treatment until as yet undetermined modifier genes or environmental factors are found, especially in the areas where the disease is prevalent.

\section{Authors' affiliations}

R Topaloglu, F Ozaltin, S Ozen, N Besbas, A Bakkaloglu, Department of Paediatric Nephrology and Rheumatology, Hacettepe University Faculty of Medicine, Ankara, Turkey

E Yilmaz, B Balci, Department of Medical Biology, Hacettepe University Faculty of Medicine

\section{REFERENCES}

1 Livneh A, Langevit P, Zemer D, Zaks N, Kees S, Lidar T, et al. Criteria for the diagnosis of familial Mediterranean fever. Arthritis Rheum 1997; 10:1879-85.

2 French FMF Consortium. A candidate gene for familial Mediterranean fever. Nat Genet 1997;17:25-31.

3 International FMF Consortium. Ancient missense mutations in a new member of the Roret gene family are likely to cause familial Mediterranean fever. Cell 1997;90:797-807.

4 Mansfield E, Chae JJ, Komarow HD, Brot TM, Frucht DM, Askentijevich I, et al. The familial Mediterranean fever protein, pyrin, associates with microtubules and colocalises with actin filaments. Blood 2001;98:851-9.

5 Touitou I. The spectrum of familial Mediterranean fever (FMF) mutations. Eur J Hum Genet 2001;9:473-83.

6 Kogan A, Shinar Y, Lidar M, Revivo A, Langevit P, Padeh S, et al. Common MEFV mutations among Jewish ethnic groups in Israel: high frequency of carrier and phenotype II states and absence of a perceptible biological advantage for carrier state. Am J Med Genet 2001;102:272-6.

7 Yalcinkaya F, Cakar N, Misirlioglu N, Tumer N, Akar N, Tekin M, et al. Genotype-phenotype correlation in a large group of Turkish patients with familial Mediterranean fever: evidence for mutation-independent amyloidosis. Rheumatology 2000;39:67-72.

8 Yilmaz E, Ozen S, Balci B, Duzova A, Topaloglu R, Besbas N, et al. Mutation frequency of familial Mediterranean fever and evidence for a high carrier rate in the Turkish population. Eur J Hum Genet 2001;9:553-5.

9 Ben-Chetrit E, Lerer I, Malamud E, Domingo C, Abeliovich D. The E148Q mutation in the MEFV gene: is it a disease causing mutation or a sequence variant? Hum Mutat 2000; 15:285-6.

10 Stoffman N, Magal N, Shohat T, Lotan R, Koman S, Oron A, et al. Higher than expected carrier rates for familial Mediterranean fever in various Jewish ethnic groups. Eur J Hum Genet 2000;8:307-10.

11 Askentijevich I, Torosyan Y, Samuels J, Centola M, Pras E, Chae JJ, et al. Mutational and haplotype studies in familial Mediterranean fever reveal new ancestral relationships and evidence for a high carrier frequency with reduced penetrance in the Ashkenazi Jewish population. Am J Hum Genet penetrance in the
1999;64:949-62.

12 Mimouni A, Magal N, Stoffman N, Shohat T, Minasian A, Krasnov M, et al. Familial Mediterranean fever: effects of genotype and ethnicity on inflammatory attacks and amyloidosis. Pediatrics 2000;105:E70.

13 Bernot A, C da Silva C, Petit JL, C Cruaud, Caloustian C, Castet V. Nonfounder mutations in the MEFV gene establish this gene as the cause of familial Mediterranean fever. Hum Mol Genet 1998;8:1317-25.

14 Booth DR, Lachmann HJ, Gillmore JD, Booth SE, Hawkins PN. Prevalence and significance of the familial Mediterranean fever gene mutation encoding pyrin Q148. QJM 2001;94:527-31.

15 Tchernitchko D, Legendre M, Cazeneuve C, Delahaye A, Niel F, Amselen S. The E148Q MEFV allele is not implicated in the development of familial Mediterranean fever. Hum Mutat 2003;22:239-40.

16 Touitou I, Magne X, Molinari N, Navarro A, Le Quellec A, Picco P, et al. MEFV mutations in Behçet's disease. Hum Mutat 2000;16:271-7.

17 Aganna E, Hawkins PN, Ozen S, Pettersson T, Bybee A, McKee SA, et al. Allelic variants in genes associated with hereditary periodic fever syndromes as susceptibility factors for reactive systemic AA amyloidosis. Genes Immun 2004; 5:289-93.

18 Ozen S, Bakkaloglu A, Yilmaz E. Pyrin Q148 mutation and familial Mediterranean fever. QJM 2002;95:332-3.

19 Tekin M, Yalcinkaya F, Cakar N, Akar N, Misirlioglu M, Tastan H, et al. MEFV mutations in multiplex families with familial Mediterranean fever: is a particular genotype necessary for amyloidosis? Clin Genet 2000;57:430-4.

20 Akar N, Akar E, Yalcinkaya F. E148Q of the MEFV gene causes amyloidosis in familial Mediterranean fever patients. Pediatrics 2001;108:215.

21 Livneh A, Langevitz P, Shinar Y, Zaks N, Kastner DL, Pras M, et al. MEFV mutation analysis in patients suffering from amyloidosis of familial Mediterranean fever. Amyloidosis 1999;6:1-6.

22 Touitou I, Picot M-C, Domingo C, Notarnicola C, Catan D, Demaille J, et al. The MICA region determines the first modifier locus in familial Mediterranean fever. Arthritis Rheum 2001;44:163-9. 